\title{
Avaliação isocinética da força muscular de atletas em função do desporto praticado, idade, sexo e posições específicas
}

J. Magalhães

J. Oliveira

A. Ascensão

J.M.C. Soares

Faculdade de Ciências do Desporto e de Educação Física

Universidade do Porto, Porto, Portugal

https://doi.org/10.5628/rpcd.01.02.13

\section{RESUMO}

A força muscular dos membros inferiores é considerada um importante factor da prestação no futebol e voleibol, como suporte de habilidades e acções motoras específicas. Por isso, tal como em outras capacidades motoras, como por exemplo a resistência, tarefas específicas, idade, sexo e diferentes funções específicas, poderão induzir diferentes padrões de desenvolvimento da força muscular. Alguns investigadores sugerem que níveis insuficientes de força poderão estar associados a um risco acrescido de lesão dos tecidos moles. Por estas razões, a avaliação e controlo da força muscular assumem uma importância particular na monitorização dos efeitos dos programas de treino bem como na despistagem de factores de risco de lesão. A avaliação isocinética da força fornece informação relevante através de indicadores como o torque máximo, as diferenças bilaterais de força e a razão antagonista/ agonista dos membros dominante e não dominante.

Deste modo, o objectivo fundamental deste trabalho foi descrever e comparar os perfis isocinéticos da força em futebolistas e voleibolistas de diferentes idades, sexo e funções específicas.

Utilizando um dinamómetro isocinético (Biodex - System 2) avaliaram-se os torques máximos concêntricos com correcção gravítica dos músculos flexores e extensores do joelho em protocolo de 5 repetições máximas à velocidade angular de $360^{\circ}$.seg. ${ }^{-1}$ (6.28 rad.seg. $\left.{ }^{-1}\right)$ e 3 repetições máximas a $90^{\circ}$. seg. ${ }^{-1}$ (1.57 rad.seg. $\left.{ }^{-1}\right)$.

Em conclusão, podemos dizer que o carácter específico da actividade funcional das modalidades desportivas estudadas, a idade e a função específica não se constituem per se factores indutores de desequilíbrio bilateral da força muscular dos membros inferiores. Contudo, no que concerne à razão $\mathrm{I} / \mathrm{Q}$ a modalidade desportiva praticada e o sexo, mesmo em sujeitos treinados, parecem ser factores que influenciam o perfil isocinético de força.

Palavras-chave: força, avaliação isocinética, futebol, voleibol

\section{ABSTRACT \\ Isokinetic strength assessment in athletes of different sports, ages, gender and positional roles}

Leg muscle strength is considered to be an important factor of performance in volleyball and soccer, supporting specific motor skills and actions. Therefore, like in other capacities such as endurance, specific tasks, age, gender and specific positional roles may induce different strength patterns. Additionally, several authors argue that strength weaknesses and/or unbalances are related to soft tissue injury risk. For these reasons, strength assessment and control is of critical value for monitoring the effects of training programs and injury risk factors. Isokinetic evaluation provides relevant information through indicators such as peak torque, bilateral strength differences in leg extensor (Ext) and flexor (Flex) muscles and antagonist/agonist strength ratios in dominant (D) and nondominant (ND) limb.

Thus, the main purpose of the present investigation was to evaluate and to compare isokinetic strength profiles of soccer and volleyball players by gender, age and different positional roles, with respect to peak torque, bilateral strength differences and antagonist/agonist ratio.

Using an isokinetic dynamometry (Biodex - System 2), soccer and volleyball players were evaluated. Maximal gravity corrected concentric peak torque of knee extensor and flexor muscles were measured during a 5-repetition at $360^{\circ}$. sec. ${ }^{-1}$ (6.28 rad.sec. $\left.{ }^{-1}\right)$ and a 3-repetition protocol at $90^{\circ}$. sec. $^{-1}(1.57$ rad.sec. $\left.{ }^{-1}\right)$.

In summary the specific demands of soccer and volleyball, age and position roles do not induce bilateral leg unbalance. However, concerning H/Q ratio, sports and gender, even in trained subjects, seem to influence isokinetic strength profile.

Key words: strength, isokinetic, testing, soccer, volleyball 


\section{INTRODUÇÃO}

A força muscular é uma importante componente da prestação desportiva. Por essa razão a avaliação da força muscular com recurso à dinamometria isocinética é largamente utilizada. Tem sido sugerido que as diferenças bilaterais de força e a razão dos torques máximos antagonista/agonista estão relacionadas com as exigências específicas dos diversos desportos $(9,10)$. Deste modo, o padrão motor de uma determinada modalidade desportiva poderá influenciar o perfil funcional dos atletas. A investigação em jogos desportivos tem demonstrado que também as posições/funções dos jogadores contribuem para uma adaptação funcional específica $(5,14,28,32)$. Por último, os estudos no domínio da aptidão física considerando o efeito da idade, do crescimento, da maturação e ainda, o efeito do treino apontam para diferenças da força muscular entre jovens e atletas adultos (para ref's ver 7,36 ). Um outro domínio da investigação tem incidido no estudo comparativo da aptidão funcional entre sujeitos de sexos distintos (8). No entanto, no que concerne a eventuais diferenças de padrão no perfil bilateral da força isocinética e da razão antagonista/agonista a informação disponível é relativamente escassa. Em jogos desportivos como o futebol e o voleibol, os grupos musculares quadriceps e os isquiotibiais são solicitados suportando diversas habilidades motoras tais como, por exemplo, a corrida, os saltos, os passes ou os remates. Estes grupos musculares que envolvem a articulação do joelho desempenham, igualmente, um importante papel na estabilidade desta articulação assim como na prevenção de lesões $(1,2,41)$. De facto, alguns estudos sugerem que a boa funcionalidade dinâmica dos músculos estabilizadores do joelho pode ser determinante na prevenção e/ou na limitação da severidade de lesões dos tecidos moles $(3,25,26)$.

Apesar de escassa, a informação disponível relativamente ao efeito da idade aponta para padrões de evolução crescente dos torques máximos e da razão antagonista/agonista $(7,20)$. Adicionalmente, os resultados da investigação relativamente ao efeito das tarefas no perfil da força muscular isocinética sugerem uma adaptação funcional específica $(9,38,39)$. Deste modo, o objectivo do presente trabalho é o de avaliar e comparar o perfil das diferenças bilaterais de força e a razão isquiotibiais/quadriceps (I/Q) em diferentes desportos, idades, sexos e funções específicas.

\section{METODOLOGIA}

$O$ presente trabalho enquadra-se num projecto de controlo e avaliação do treino de atletas de alto rendimento sendo composto por três estudos distintos. No primeiro (Estudo 1) descrevemos e comparamos o perfil isocinético da força muscular de atletas de diferentes desportos (voleibolistas vs. futebolistas) e idades. No segundo (Estudo 2) comparamos sujeitos de sexo diferente relativamente à razão antagonista/agonista. Finalmente, no terceiro (Estudo 3) comparamos perfis de atletas de diferentes funções específicas.

\section{AMOSTRA \\ Estudo 1}

Foram avaliados vinte e oito (28) voleibolistas adultos de elite subdivididos em dois grupos, dezoito (18) seniores (idade: $23.9 \pm 2.3$ anos; peso: $83.6 \pm 5.8 \mathrm{Kg}$; altura: $190.8 \pm 4.5 \mathrm{~cm})$ e dez $(10)$ juniores (idade: $17.3 \pm 0.8$ anos; peso: $82.6 \pm 9.3 \mathrm{Kg}$; altura: $188.2 \pm 2.9 \mathrm{~cm}$ ), catorze (14) voleibolistas de elite sub-16 e quarenta e seis (46) futebolistas adultos de elite (idade: $25.2 \pm 3.5$ anos; peso: $75.3 \pm 6.0 \mathrm{Kg}$; altura: $178.3 \pm 6.0 \mathrm{~cm}$ ).

\section{Estudo 2}

Avaliaram-se vinte e cinco (25) voleibolistas do sexo masculino pertencendo à selecção nacional portuguesa (idade: $21.0 \pm 3.7$ anos; peso: $83.6 \pm 6.2$ Kg; altura: $190.9 \pm 3.8 \mathrm{~cm}$ ) e dez (10) voleibolistas do sexo feminino de uma equipa da $1^{\text {a }}$ divisão do campeonato nacional (idade: $25.0 \pm 4.3$ anos; peso: $70.0 \pm 4.9 \mathrm{Kg}$; altura: $178.5 \pm 3.3 \mathrm{~cm}$ ).

\section{Estudo 3}

Foram avaliados quarenta e sete (47) futebolistas profissionais (idade: $25.1 \pm 3.6$ anos; peso: $75.2 \pm 7.3$ kg; altura: $178.8 \pm 4.0 \mathrm{~cm}$ ) de diferentes equipas da I Liga Profissional portuguesa. Deste grupo de sujeitos avaliamos três (3) guarda-redes, seis (6) laterais, dez (10) centrais, quinze (15) médios e treze (13) avançados. 


\section{INSTRUMENTOS E PROCEDIMENTOS DE AVALIAÇÃO}

Foram avaliados em dinamómetro isocinético (Biodex

- System 2) com correcção gravítica os torques máximos concêntricos dos músculos flexores e extensores do joelho às velocidades angulares de $360^{\circ}$.seg. -1 $^{1}$ (6.28 rad.seg. $\left.{ }^{-1}\right)$ e $90^{\circ}$.seg. ${ }^{-1}$ (1.57 rad.seg.-1). No Estudo 3 apenas se considerou a última das velocidades angulares referidas.

Os atletas avaliados realizaram um período de activação geral em cicloergómetro (Monark E-824) com uma resistência correspondente a $2 \%$ do peso corporal durante um período de 5 minutos. Em seguida os sujeitos foram sentados na cadeira do dinamómetro e estabilizado o seu posicionamento com recurso a cintos colocados ao nível do tronco, do abdómen e da coxa, no sentido de prevenir movimentos acessórios. O joelho a avaliar foi posicionado a $90^{\circ}$ da flexão $\left(0^{\circ}=\right.$ extensão completa $)$ e o eixo de rotação do braço da alavanca do dinamómetro alinhado com a parte lateral do côndilo femoral. Após os procedimentos de posicionamento e dos alinhamentos foi pedido aos sujeitos a testar que efectuassem alguns movimentos de flexão e extensão a intensidade sub-máxima no sentido de completar o período de activação muscular e também para familiarização com o equipamento e procedimentos de testagem. Todos os sujeitos foram instruídos para colocarem de forma confortável os braços cruzados sobre o tronco tendo em vista o isolamento da acção dos grupos musculares responsáveis pela extensão e flexão do joelho.

\section{Protocolo de avaliação}

A avaliação consistiu na realização de 5 repetições à velocidade angular de $360^{\circ}$. seg. ${ }^{-1}$ e 3 repetições a $90^{\circ}$.seg. ${ }^{-1}$, por esta ordem e em cada um dos membros. Entre séries foi realizada uma pausa de repouso com a duração de 1,5 minutos. Para o estudo 3 apenas foram realizadas avaliações a $90^{\circ}$. seg. ${ }^{-1}$

\section{Estatística}

Foram utilizadas as medidas da estatística descritiva, média e desvio-padrão e para a comparação de médias o $t$-Test de medidas independentes, a ANOVA factorial e o teste não paramétrico Kruskall-Wallis. O nível de significância foi estabelecido em $5 \%$.

\section{RESULTADOS}

\section{Estudo 1}

Os principais resultados acerca da comparação entre futebolistas e voleibolistas são apresentados no quadro 1.

Quadro 1 - Diferenças bilaterais de força (\%) e razão (\%) isquiotibiais/ quadriceps $(\mathrm{I} / \mathrm{Q})$ dos futebolistas vs. voleibolistas adultos, a diferentes velocidades angulares.

\begin{tabular}{|c|c|c|c|c|c|}
\hline Vel. & Diferençą & as bilaterai & $s$ de força & Raz & ตัo $1 / Q$ \\
\hline & Músculos & Futebol & Voleibol & Futebol & Voleibol \\
\hline 360 & Extensores & $7.1 \pm 6.3$ & $7.2 \pm$ & $D^{\#} 80.2 \pm 13.3$ & 78.3 \\
\hline 90 & & $7.1 \pm 6.3$ & $10.1 \pm 6.9$ & $57.4 \pm 6.7$ & $50.4 \pm 7.2 * *$ \\
\hline 360 & Flexores & $12.3 \pm 8.4$ & $14.2 \pm 12.4$ & $\mathrm{ND}^{\#} 82.5 \pm 13.3$ & $82.0 \pm 11.9$ \\
\hline 90 & & $10.6 \pm 8.0$ & $6.9 \pm 5.5^{* *}$ & $56.1 \pm 8.2$ & $50.5 \pm 6.4^{* *}$ \\
\hline
\end{tabular}

${ }^{*}\left({ }^{\circ}\right.$.seg. $\left.{ }^{-1}\right) * *$ Diferença significativa (futebolistas vs.

voleibolistas); $p<0,05$

\# $D$ (membro dominante); ND (membro não dominante).

Os resultados que se reportam às diferenças bilaterais de força entre futebolistas e voleibolistas adultos mostram que apenas nos músculos flexores, quando avaliados à velocidade de $90^{\circ}$. seg. ${ }^{-1}$, se encontram diferenças significativas. A comparação das razões I/Q revelou-se estatisticamente significativa entre grupos, mas apenas à velocidade angular de $90^{\circ}$.seg. ${ }^{-1}$. Porém, a comparação de médias da razão I/Q entre os membros dominante e não dominante dentro de cada grupo, não apresentou diferenças significativas.

Os resultados das diferenças bilaterais de força e da razão I/Q em voleibolistas de diferentes idades são apresentados no quadro 2 . 
Quadro 2 - Diferenças bilaterais de força (\%) e razão (\%) isquiotibiais/quadriceps (I/Q) em voleibolistas de diferentes idades.

\begin{tabular}{|c|c|c|c|c|c|c|c|c|}
\hline \multirow[t]{2}{*}{ Vel.* } & & \multicolumn{3}{|c|}{ Diferenças bilaterais de força } & \multirow[b]{2}{*}{ \# } & \multicolumn{3}{|c|}{ Razão I/Q } \\
\hline & & Seniores & Juniores & Sub 16 & & Seniores & Juniores & Sub 16 \\
\hline 360 & Extensores & $7.8 \pm 6.2$ & $7.0 \pm 5.4$ & $7.8 \pm 5.2$ & D & $74.0 \pm 13.5$ & $83.5 \pm 13.2$ & $61.9 \pm 14.0^{* *}$ \\
\hline 90 & & $8.9 \pm 5.9$ & $14.8 \pm 12.0$ & $7.2 \pm 5.8$ & & $50.1 \pm 8.6$ & $50.4 \pm 3.7$ & $48.0 \pm 4.2$ \\
\hline 360 & Flexores & $10.8 \pm 7.5$ & $14.0 \pm 7.8$ & $14.8 \pm 16.5$ & ND & $81.5 \pm 10.4$ & $83.2 \pm 14.7$ & $75.9 \pm 12.8$ \\
\hline 90 & & $5.1 \pm 4.5$ & $10.2 \pm 6.4$ & $9.6 \pm 7.2$ & & $50.4 \pm 5.8$ & $52.4 \pm 9.2$ & $51.1 \pm 9.4$ \\
\hline
\end{tabular}

*Velocidade ( ${ }^{\circ}$. seg. $\left.{ }^{-1}\right)$; \# D (membro dominante); ND (membro não dominante)

** Diferença significativa (juniores vs. Sub 16); $p<0,05$

A análise dos resultados revela a existência de diferenças significativas na razão I/Q entre a categoria júnior e a de sub 16.

\section{Estudo 2}

Os principais resultados são apresentados no quadro 3 (razão I/Q em percentagem).

Quadro 3 - Razão I/Q (\%) em ambos os sexos a diferentes velocidades $\left(\mathrm{em}^{\circ}\right.$.seg. $\left.^{-1}\right)$

\begin{tabular}{lrcc} 
Velocidade & Membro & Masculino & Feminino \\
\hline 360 & Dominante & $80,03 \pm 13,14^{*}$ & $66,77 \pm 13$ \\
& Não Dominante & $83,88 \pm 12,12$ & $75,81 \pm 9,28$ \\
90 & Dominante & $50,07 \pm 7,28^{*}$ & $44,06 \pm 6,96$ \\
& Não Dominante & $50,72 \pm 7,43 *$ & $44,47 \pm 4,16$
\end{tabular}

* estatisticamente significativo (masculino vs. feminino) p 0,05

A razão convencional concêntrica I/Q aumentou com a velocidade angular, quer nos sujeitos do sexo masculino, quer nos do sexo feminino (quadro 3). Foram encontradas diferenças estatisticamente significativas entre os grupos no membro dominante a altas velocidades $\left(360^{\circ}\right.$. seg. $\left.{ }^{-1}\right)$ e nos membros dominante e não dominante a baixas velocidades (90 ${ }^{\circ}$.seg. $\left.{ }^{-1}\right)$. Este indicador, quando determinado a baixa velocidade $\left(90^{\circ}\right.$.seg. $\left.{ }^{-1}\right)$, apresentou valores inferiores aos habitualmente sugeridos como referência.

\section{Estudo 3}

Para a globalidade da amostra, os valores médios das diferenças bilaterais de força nos músculos extensores e flexores foram $8.2 \% \pm 4.9$ e $7.9 \% \pm 4.7$, respectivamente. A razão I/Q (em percentagem) no membro dominante foi de $54.9 \pm 6.6$ e no não dominante de $55.9 \pm 6.4$.

Os resultados referentes a cada uma das funções específicas são apresentados no quadro 4 .

Quadro 4 - Torque máximo (Nm), diferenças bilaterais (\%) e razão I/Q (\%) em futebolistas de diferentes funções específicas.

Torque máximo

Funções

G-Redes

Centrais

Laterais

Médios

Avançados

\section{Torque máximo}

Ext - D Ext - ND Flex - D Flex - ND

\section{Diferenças bilaterais}

$\begin{array}{cccccccc}278.6 \pm 27.6 & 240.9 \pm 16.8 & 148.8 \pm 27.3 & 132.3 \pm 26.4 & 13.3 \pm 4.411 .3 \pm 2.0 & 53.1 \pm 4.9 & 54.6 \pm 7.8 \\ 244.4 \pm 25.5 & 237.6 \pm 21.5 & 124.5 \pm 6.7 & 125.6 \pm 16.1 & 10.1 \pm 7.9 & 9.0 \pm 8.2 & 51.4 \pm 5.9 & 53.3 \pm 9.7 \\ 250.9 \pm 31.5 & 237.9 \pm 33 & 141.9 \pm 15.1 & 134.4 \pm 14.1 & 8.4 \pm 5.7 & 6.4 \pm 3.5 & 56.8 \pm 6.9 & 57.1 \pm 7.2 \\ 227.4 \pm 24.3 & 216.9 \pm 28.5 & 124.9 \pm 19.4 & 123.4 \pm 19.1 & 5.6 \pm 4.2 & 9.2 \pm 7.5 & 55.2 \pm 6.7 & 56.7 \pm 5.2 \\ 241.1 \pm 42.2 & 231.5 \pm 32.6 & 130.9 \pm 20.3 & 128.8 \pm 21.2 & 8.2 \pm 6.4 & 6.9 \pm 2.8 & 54.8 \pm 7.0 & 55.6 \pm 5.4\end{array}$




\section{DISCUSSÃO}

Os resultados do estudo 1 não evidenciaram diferenças bilaterais de força entre voleibolistas e futebolistas, com excepção da diferença significativa encontrada nos músculos flexores do joelho quando avaliados a $90^{\circ} . \mathrm{seg}^{-1}$. Estes resultados parecem realçar o carácter bilateral destas modalidades. Efectivamente, a frequente utilização de algumas habilidades específicas do futebol com manifesta preferência lateral, como por exemplo o passe, o remate, os tackles e/ou aspectos específicos do treino, contrariamente ao que seria de esperar, não induzem incrementos pronunciados da força no membro dominante e, consequentemente, diferenças bilaterais acentuadas. Também Bennell et al. (6) não encontraram diferenças bilaterais significativas nos músculos flexores do joelho em 102 jogadores de futebol australiano. No entanto, num estudo efectuado por Wang et al. (39) em voleibolistas, foram encontradas diferenças significativas de força nos músculos rotadores do ombro, quando avaliados em modo isocinético, entre o membro superior dominante e não dominante. Para os autores, a utilização sistemática de um dos membros relativamente ao outro nas acções de remate e do serviço poderá justificar as diferenças encontradas. Deste modo, e tendo em conta que no voleibol a lógica da utilização dos membros superiores é análoga à dos membros inferiores no futebol, a ausência de diferenças entre os grupos do nosso estudo poderá eventualmente ser explicada: (i) pela participação mais activa e diferenciada quanto ao modo contráctil do membro inferior não dominante nas acções de passe e remate do futebolista (27); (ii) pela menor frequência absoluta da realização de acções unilaterais de alta intensidade do futebolista comparativamente com as acções de serviço e remate utilizadas pelos voleibolistas (para refs ver 28, 33). Efectivamente, num estudo com jovens futebolistas italianos(11), a exemplo dos nossos resultados, não foram encontradas diferenças bilaterais de força entre os membros dominante e não dominante. Mognoni et al. (30) encontraram torques máximos mais elevados na extensão do joelho do membro inferior não dominante comparativamente ao dominante, ainda que não tenham referido o modo de contracção utilizado. Estes resultados realçam a importância da intensidade do trabalho desenvolvido pelo membro inferior não dominante, como perna de apoio, na realização de algumas acções motoras características do futebol e, consequentemente, reflectem a influência destas acções nos ganhos de força do membro contralateral.

De salientar ainda no nosso estudo que, para ambas as modalidades, todos os valores encontrados neste parâmetro se encontram dentro dos critérios considerados adequados, i.e., inferiores a $10-15 \%$ (9), podendo por isso considerar-se que os voleibolistas e os futebolistas são atletas funcionalmente equilibrados (quadro 1).

A razão de força antagonista/agonista tem sido associada com as exigências específicas da actividade funcional dos desportos (10). Os nossos resultados parecem confirmar este facto. À velocidade angular de $90^{\circ}$.seg. ${ }^{-1}$ encontramos diferenças significativas entre os voleibolistas e futebolistas. Os primeiros apresentam uma razão mais baixa do que os futebolistas, por apresentarem maior fraqueza dos isquiotibiais. Este facto pode dever-se às características da modalidade (29), o que no caso do voleibol resulta para o quadriceps numa solicitação frequente em muitas das acções típicas, ou/e por insuficiente trabalho compensatório de força dos músculos isquiotibiais. Pese embora possamos estar perante um facto resultante de uma adaptação específica às exigências do voleibol, este facto pode representar um factor de risco acrescido à ocorrência de lesões nos tecidos moles $(4,29,40,41)$. Segundo Aagaard et al. (3), valores da razão I/Q inferiores a cerca de $60 \%$, quando avaliados a baixas velocidades, poderão aumentar a susceptibilidade de ocorrência de lesões. Alguns autores (para ref.'s ver 20) sugerem que os aumentos acentuados da força do quadriceps induzidos pelo treino poderão estar associados à diminuição da co-activação antagonista dos músculos isquiotibiais (37), favorecendo a susceptibilidade de lesões no joelho, nomeadamente de stress tensional no ligamento cruzado anterior (LCA), por decréscimo das forças estabilizadoras desta articulação.

Diversos autores $(1,3,24)$ têm sugerido que a razão I/ Q poderá ser interpretada como um indicador da capacidade dos isquiotibiais em contrariar a translação anterior da tíbia relativamente ao fémur 
(shear forces), particularmente nos últimos ângulos de extensão do joelho e durante a realização de contracções intensas do quadriceps. Da mesma forma, os resultados de alguns estudos com recurso à electromiografia $(1,15)$ sugerem que a co-activação dos isquiotibiais, nomeadamente do biceps femoral (1), poderá também representar um mecanismo de estabilidade articular durante a rotação interna da tíbia na extensão do joelho. De facto, devido à localização externa da inserção distal deste músculo, a rotação interna da tíbia nos movimentos de extensão do joelho parece ser contrariada pela acção antagonista do biceps femoral. Por estas razões, estes autores sugerem que a força produzida pelos isquiotibiais enquanto antagonistas no movimento de extensão do joelho, poderá determinar índices de co-activação com carácter de protecção funcional da articulação, nomeadamente da integridade do LCA. Este ligamento, sendo considerado uma das estruturas mais importantes na restrição da amplitude do movimento de gaveta da tíbia relativamente ao fémur durante a extensão do joelho, é sujeito a grande stress (29). Por isso, no estudo epidemiológico das lesões nos jogos desportivos colectivos $(16,17,21)$, a lesão do LCA constitui-se como uma das mais frequentes (34). Em estudos com animais e humanos (15) tem sido referida a existência de um mecanismo de reflexo neural por parte do LCA na activação dos isquiotibiais e também dos gémeos (15) durante a extensão do joelho. Para além disso, DeLuca e Mambrito(13) sugerem que em alguns tipos de movimentos, nomeadamente naqueles em que de forma antecipada é prevista uma resposta neuromuscular compensatória, parece existir um mecanismo de condução neural comum, ou também denominado de activação neural proporcional, em que o sistema nervoso central parece controlar de forma sistemática e coordenada a activação de motoneurónios agonistas e antagonistas. Desta forma, parece provável que movimentos de extensão do joelho representem situações em que, por um mecanismo de activação neural proporcional agonista-antagonista, a força compensatória produzida pelos isquiotibiais é antecipada diminuindo o stress induzido ao LCA pela contracção do quadriceps.
Num estudo com velocistas (22) foi analisada a importância da força produzida pelos isquiotibiais como factor de prevenção de lesões neste mesmo grupo muscular. Verificou-se que os atletas lesionados, quando comparados com os não lesionados, apresentavam baixos índices de força nesse grupo muscular e, consequentemente, da razão I/Q quando avaliada de forma excêntrica num amplo espectro de velocidades angulares e de forma concêntrica a $30^{\circ}$.seg. ${ }^{-1}$. Desta forma, poderemos considerar este parâmetro isocinético como uma importante referência da estabilidade da articulação do joelho e da prevenção de lesões nos músculos flexores.

De salientar ainda que estudos comparativos das alterações neuromusculares induzidas por diferentes tipos de exercício sugerem que, após exercício intenso prolongado do tipo intermitente, se registam diminuições significativas da força muscular gerada pelos isquiotibiais e incrementos no tempo de atraso electromecânico deste grupo muscular. Estes factos não só comprometem a estabilidade da articulação do joelho por aumento da laxidez articular, como representam uma forte ameaça à integridade do LCA (18, 29). Desta forma, realça-se a importância da força produzida pelos isquiotibiais, enquanto músculos antagonistas, como factor de prevenção da integridade desta articulação, em especial durante a realização de exercícios intensos e prolongados de carácter intermitente, como por exemplo um jogo de futebol ou de voleibol.

Segundo Aagaard et al. $(3,4)$ a razão entre o torque máximo dos isquiotibiais no modo excêntrico e o torque máximo do quadriceps no modo concêntrico, ao contrário da por nós utilizada (concêntrico/ concêntrico), parece ser, do ponto de vista funcional, mais específica do padrão de movimentos de flexão e extensão realizados em torno da articulação do joelho em determinadas acções motoras, como por exemplo o remate do futebolista. Nesta perspectiva, a avaliação dos músculos flexores do joelho é realizada no modo excêntrico, já que esse é o padrão de co-activação desenvolvido enquanto grupo muscular antagonista em diversas acções motoras, particularmente na desaceleração do membro inferior nas últimas fases da extensão do joelho. No entanto, este método de avaliação poderá apresentar 
dificuldades de operacionalização, tornando-se inviável como instrumento massivo de controlo e acompanhamento do treino em atletas de alto rendimento. A avaliação desta relação de força no modo concêntrico/excêntrico pode não só revelar-se muito demorada em virtude das características técnicas do dinamómetro, como também ser influenciada pelo factor aprendizagem. Devido à sua elevada exigência coordenativa, a avaliação de movimentos isocinéticos no modo excêntrico, sem experiências anteriores, é complexa, podendo distorcer os resultados.

Os dados relativos às diferenças bilaterais de força e da razão I/Q em diferentes idades, com excepção da razão I/Q entre atletas juniores e sub16 no membro dominante a $360^{\circ}$.seg.-1, não evidenciaram diferenças significativas entre os grupos. Do nosso conhecimento, não existem estudos acerca do efeito da idade no perfil de força muscular, avaliada em dinamómetros isocinéticos em voleibolistas. Contudo, num estudo efectuado com futebolistas de elite (20) foram encontradas diferenças significativas na razão recíproca (torque excêntrico máximo dos isquiotibiais dividido pelo torque concêntrico máximo do quadriceps) do membro inferior dominante com a idade. $\mathrm{O}$ facto de tais diferenças não terem sido igualmente encontradas no membro inferior não dominante, levou os autores a concluir que provavelmente o efeito da adaptação ao treino específico, nomeadamente pela maior carga excêntrica a que está sujeito o membro dominante no futebol de alto nível, poderá ter tido maior influência na diferenciação da razão I/Q do que o factor idade. De salientar ainda que, no referido estudo, tais diferenças reportam-se a avaliações realizadas em modos de contracção diferentes daqueles por nós utilizados. Porém, quando avaliados no modo concêntrico/concêntrico, a exemplo dos nossos resultados, os autores não encontraram diferenças significativas entre os grupos de diferentes idades. No mesmo estudo, nas avaliações realizadas no modo excêntrico/excêntrico, a razão I/Q alterou-se significativamente com a idade em todo o espectro de velocidades angulares utilizado. No que diz respeito à razão recíproca (excêntrico/concêntrico), apenas à velocidade angular de $300^{\circ}$.seg..$^{-1}$ foram encontradas diferenças significativas entre futebolistas jovens e adultos. Assim, considerando a nossa amostra e de acordo com os resultados obtidos, ao contrário do sugerido por Calmels e Minaire (10) não parece existir um padrão diferenciado de desenvolvimento da força do quadriceps e dos isquiotibiais com a idade. Assim sendo, a idade não parece induzir alterações significativas no padrão do equilíbrio bilateral da força muscular dos membros inferiores e na razão antagonista/agonista quando avaliada no modo concêntrico.

Os resultados obtidos no estudo 2 quanto à razão I/ $Q$ revelam que, à excepção do membro não dominante a $360^{\circ}$.seg.-1 ${ }^{-1}$ os sujeitos do sexo feminino apresentam valores significativamente mais baixos do que os do sexo masculino. Para além disso, ambos os grupos, com especial destaque para o do sexo feminino, apresentam valores que podemos considerar baixos. Tal como sugerido na discussão dos resultados do estudo 1 , a explicação para este facto poderá advir das características funcionais das principais acções de jogo. De facto, no voleibol, a hipersolicitação do grupo muscular quadriceps e/ou um reduzido treino de força dos seus antagonistas poderá explicar este perfil de força. De forma idêntica aos nossos resultados, Griffin et al. (19) verificaram que em sujeitos adultos destreinados a razão $\mathrm{I} / \mathrm{Q}$ independentemente do tipo de contracção e das velocidades utilizadas, era significativamente inferior no sexo feminino. Assim, sugerimos que o treino do voleibol não será, por si só, susceptível de alterar as diferenças relativas de força entre os isquiotibiais e o quadriceps, mantendo-se o efeito do sexo mesmo em sujeitos treinados. Dada a escassez de estudos que reproduzam e esclareçam, de forma clara, o efeito do sexo nas alterações da razão I/Q provavelmente $o$ recurso ao estudo de factores de natureza morfológica, mecânica e neuromuscular poderá concorrer para uma explicação adicional da influência do sexo neste parâmetro.

De acordo com os resultados obtidos no estudo 3, as diferentes funções específicas dos futebolistas e a inerente actividade funcional que lhes está associada não parecem induzir padrões distintos no perfil isocinético da força muscular dos membros inferiores. A similaridade encontrada no nosso 
estudo entre as diferentes funções específicas contraria a tendência dos resultados obtidos num outro estudo (38), pelo menos no que diz respeito aos torques máximos entre guarda-redes e avançados, quando determinados a baixas velocidades. Porém, nesse estudo não é fornecida qualquer informação acerca das diferenças bilaterais ou da razão I/Q. Da mesma forma, Oberg et al. (31) verificaram que a razão I/Q é significativamente mais elevada nos avançados comparativamente com os guarda-redes e defesas. Para estes autores, os elevados torques obtidos na avaliação dos músculos extensores do joelho nos guarda-redes e defesas poderão justificar os baixos valores da razão I/Q. Eventualmente, alterações da metodologia do treino, da concepção do jogo, nomeadamente a maior atenção ao treino compensatório da força muscular e a polivalência de tarefas realizadas, bem como a crescente utilização indiferenciada da técnica com ambos os membros, terão conduzido nos últimos anos a uma indiferenciação do perfil de força muscular dos futebolistas de diferentes posições específicas, justificando os nossos resultados.

As diferenças bilaterais de força e a razão I/Q encontradas nos futebolistas das diferentes posições específicas vão de encontro aos valores normativos sugeridos na literatura $(3,9,10,23,35)$ para avaliações a baixa velocidade (inferiores a $10-15 \%$ e cerca de 50 $60 \%$, respectivamente) e por nós encontrados no estudo 1. De facto, apesar de algumas habilidades específicas do futebol serem habitualmente realizadas em jogo ou no treino com preferência lateral, os nossos resultados sugerem que, independentemente da função desempenhada, os atletas avaliados são funcionalmente equilibrados. No que diz respeito à razão $\mathrm{I} / \mathrm{Q}$, os valores médios obtidos em atletas de algumas posições específicas (e.g. centrais e guarda-redes) encontram-se próximos dos valores mínimos referidos como adequados, o que poderá ser justificado quer pela elevada predominância de solicitação do grupo muscular quadriceps em algumas habilidades técnicas, quer pelo insuficiente treino compensatório da força dos músculos isquiotibiais. De facto, De Proft et al. (12) registaram um incremento de $77 \%$ no torque máximo dos flexores do joelho quando introduziram duas sessões semanais de treino de força para esse grupo muscular no programa anual de uma equipa de futebol belga. Na opinião dos autores, esta alteração pronunciada poderá significar uma insuficiente solicitação deste grupo muscular durante as acções típicas do futebol em treino e na competição e, portanto, a necessidade de treino compensatório sistemático.

Em conclusão e tendo em conta os resultados dos nossos estudos, podemos dizer que o carácter específico da actividade funcional das modalidades desportivas estudadas, a idade e a função específica não se constituem per se factores indutores de desequilíbrio bilateral da força muscular dos membros inferiores. Contudo, no que concerne à razão I/Q, a modalidade desportiva praticada e o sexo, mesmo em sujeitos treinados, parecem ser factores que influenciam o perfil isocinético de força.

\section{CORRESPONDÊNCIA}

José Oliveira

Faculdade de Ciências do Desporto

e de Educação Física

Universidade do Porto

R. Dr. Plácido Costa, 91

4200.450 Porto

Portugal

[joliveira@fcdef.up.pt] 


\section{REFERÊNCIAS}

1. Aagaard P, Simonsen EB, Andersen JL, Magnusson SP, BojsenMøller F, Dyhre-Poulsen P (2000). Antagonist muscle coactivation during knee extension. Scand J Med Sci Sports 10: 58-67 2. Aagaard P, Simonsen EB, Beyer N, Larsson B, Magnusson SP, Kjaer M (1997). Isokinetic muscle strength and capacity for muscular knee joint stabilization in elite sailors. Int J Sports Med 18 (7): 521-525

3. Aagaard P, Simonsen EB, Magnusson SP, Larsson B, DyhrePoulsen P (1998). A New Concept for Isokinetic Hamstring/ Quadriceps Muscle Strength Ratio. Am J Sports Med 26 (2): 231-237 4. Aagaard P, Simonsen EB, Trolle M, Bangsbo J, Klausen K (1995). Isokinetic hamstring/quadriceps strength ratio: influence from joint angular velocity, gravity correction and contraction mode. Acta Physiol Scand 154 (4): 421-427 5. Bangsbo J (1993). The Physiology of Soccer - with Special Reference to Intense Intermittent Exercise. Acta Physiol Scand, vol.151 Supplementum 619: 1-156.

6. Bennell K, Wajswelner H, Lew P, Schall-Riaucour A, Leslie S, Plant D, Cirone J (1998). Isokinetic strength testing does not predict hamstring injury in Australian Rules footballers. $\mathrm{Br} \mathrm{J}$ Sports Med, 32: 309-314

7. Beunen G, Thomis M (2000). Muscular strength development in children and adolescents. Ped Exerc Sci 12 (2): 174-197 8. Blimkie CJR (1989). Age- and sex-associated variation in strength during childhood:anthropometric, morphologic, neurologic, biomechanical, endocrinologic, genetic, and physical activity correlates. In CV Gisolfi e DR Lamb (Eds), Youth exercise and sport, Indianapolis, IN: Benchmark Press, 99-161.

9. Brown, L. (2000). Isokinetics in Human Performance, Champaign, IL: Human Kinetics.

10. Calmels P, Minaire, P (1995). A Review of the role of the agonist/antagonist muscle pairs ratio in rehabilitation. Disability and Rehabilitation 17 (6): 265-276

11. Capranica L, Cama G, Fanton F, Tessitore A, Figura F (1992). Force and power of preferred and non-preferred leg in young soccer players. J Sports Med Phys Fitness, 32: 358-363 12. De Proft E, Cabri J, Doufour W, Clarys J (1988). Strength training and kick performance in soccer players. In Reilly, T; Lees, A; Davids K; Murphy, W (eds.) Science and Football. London-New York: E \& FN Spon: 108-113

13. DeLuca CJ, Mambrito B (1987). Voluntary control of motor units in human antagonist muscles: co-activation and reciprocal activation. J Neuralphysiol, 58: 525-542 14. Dyba W (1982). Physiological and activity characteristics of volleyball. Volley Tech Journal, 6 (3): 33-51

15. Dyhre-Poulsen P, Krogsgaard MR (2000). Muscular reflexes elicited by electrical stimulation of the anterior cruciate ligament in humans. J Appl Physiol, 89: 2191-2195

16. Ekstrand J, Gillquist J (1983). Soccer injuries and their mechanisms: a prospective study. Med Sci Sports Exerc 15 (3): 267-270

17. Ekstrand J, Gillquist J (1983). The avoidability of soccer injuries. Int J Sports Med 4 (2): 124-128

18. Gleeson NP, Reilly T, Mercer TH, Rakowski S, Rees D (1998). Influence of acute endurance activity on leg neuromuscular and muscular skeletal performance. Med Sci Sports Exerc, 30(4): 596-608

19. Griffin JW, Tooms RE, vander Zwaag R, Bertorini TE, O'Toole ML (1993). Eccentric muscle performance of elbow and knee muscle groups in untrained men and women. Med Sci Sports Exerc, 25(8): 936-944

20. Gür H, Akova B, Pündük Z, Küçükoglu S (1999).Effects of age on the reciprocal peak torque ratios during knee muscle contractions in elite soccer players. Scand J Med Sci Sports 9: 81-87 21. Inklaar H (1994). Soccer Injuries I: Aetiology and Prevention. Sports Med 18 (2): 81-93

22. Jönhagem S, Nemethe G, Eriksson E (1994). Hamstring injuries in sprinters: the role of concentric and eccentric hamstring muscles strength and flexibility. Am J Sports Med, 22: 262-266 23. Kannus P (1994). Isokinetic evaluation of muscular performance: implications for muscle testing and rehabilitation. Int J Sports Med, 15 (Suppl 1): S11-S18 24. Kellis E, Baltzapoulos V (1995). Isokinetic eccentric exercise. Sports Med 19 (3): 202-222

25. Kellis E, Baltzopoulos V (1997). Muscle Activation Differences Between Eccentric and Concentric Isokinetic Exercise. Med ScI Sports Exerc 1616-1623

26. Kellis E, Baltzopoulos V (1997). The Effects of Antagonist Moment on the Resultant Knee Joint Moment during Isokinetic Testing of knee Extensors. Eur J Appl Physiol 76: 253-259

27. Lees A, Nolan L (1998) The biomechanics of soccer: A review. J Sport Sci, 16: 211-234

28. MacLaren D (1990). Court Games: Volleyball and Basketball. In T Reilly, N Secher, P Snell (Eds), Physiology of Sports, London: E \& F Spon, 427-464

29. Mercer TH, Gleeson NP, Claridge S, Clement S (1998). Prolonged intermittent high intensity exercise impairs neuromuscular performance of the knee flexors. Eur J Appl Physiol, 77: 560-562

30. Mognoni P, Narici MV, Sirtori MD, Lorenzelli F (1994). Isokinetic torques and kicking maximal ball velocity in young soccer players. J Sports Med Phys Fitness, 34: 357-361

31. Oberg B, Ekstrand J, Moller M, Gillquist J (1984). Muscle strength and flexibility in different positions of soccer players. Int J Sports Med, 5 (4): 213-216

32. Oliveira J (2000). Avaliação da resistência em desportos de esforço intermitente. Dissertação apresentada a provas de Doutoramento, Porto: FCDEF-UP (não publicado)

33. Olsen E, Larsen O (1997). Use of match analysis by coaches. In T Reilly, J Bangsbo, M Hughes (Eds), Science and Football III, London: E\&Fspon, 209-220

34. Østerås H, Augestad LB, Tøndel S (1998). Isokinetic muscle strength after anterior ligament reconstruction. Scand J Med Sci Sports, 8: 279-282

35. Perrin DH (1993). Isokinetic Exercise and Assessment.

Champaign, Illinois: Human Kinetics Publishers

36. Sale D (1989). Strength training in children. In CV Gisolfi e DR Lamb (Eds), Youth, exercise and sport. Perspectives in Exercise Science and Sports Medicine, Vol. II, Indianapolis, IN: Benchmark Press, $165-222$

37. Spurway NC, Watson H, McMillan K, Connolly G (2000). The effect of strength training on the apparent inhibition of eccentric force production in voluntarily activated human quadriceps. Eur J Appl Physiol, 82: 374-380

38. Togary H, Ohashi J, Ohgushi T (1988). Isokinetic muscle strength of soccer players. In: Reilly, T; Lees, A; Davids K; Murphy, W (eds.) Science and Football. London-New York: E \& FN Spon: 181-185

39. Wang H, MacFarlane A, Cochrane T (2000). Isokinetic performance and shoulder mobility in elite volleyball athletes from the United Kingdom. Br J Sports Med, 34: 39-43 40. Yamamoto T. (1993). Relationship between hamstrings strains and leg muscle strength. A follow-up study of collegiate track and field athletes. J Sports Med Phys Fitness, 33: 194-199 41. Zakas A, Mandroukas K, Vamvakoudis E, Christoulas K, Agelopoulou N. (1995). Peak torque of quadriceps and hamstring muscles in basketball and soccer players of different divisions. J Sports Med Phys Fitness 35 (3): 199-205 